\title{
Basic Values in Russia: \\ Their Dynamics, Ethnocultural Differences, and Relation to Economic Attitudes
}

\author{
Nadezhda Lebedeva ${ }^{\mathrm{a}, \mathrm{b}}$, Alexander Tatarko $^{\mathrm{a}, \mathrm{b}^{*}}$ \\ a National Research University Higher School of Economics, Moscow, Russia \\ ${ }^{\mathrm{b}}$ Institute of Psychology of Russian Academy of Sciences, Moscow, Russia \\ *Corresponding author. E-mail: tatarko@yandex.ru
}

Background. This study was carried out using the framework of S. Schwartz's theory of basic human values.

Objective. This article examines the dynamics of the basic values of Russians (20082016) and the relationship between value orientations and economic attitudes among Christians and Muslims in Russia.

Design. The dynamics of values of Russians were analyzed based on the five waves rounds of ESS $(2006,2008,2010,2012,2016)$, each of which included around 2,000 respondents. The 2010 sample included ethnic Russians as well as respondents from the North Caucasus $(\mathrm{N}=278)$.

Results. We found that the most preferred value among Russians is Security. However, the importance of this value decreased over 10 years (2006-2016). Such values as Achievement, Tradition, and Power were relatively stable among Russians during this period. In addition, between 2006 and 2016 we observed the increasing priority of the values of Hedonism and Stimulation. Using our own data set, we examined the relations between values and attitudes toward different types of economic behavior.

Conclusion. We found that the patterns of the relations between values and attitudes toward different types of economic behavior had similarities as well as differences among Christians (in the Central Federal District and the North Caucasus Federal District) and Muslims (in the North Caucasus Federal District) in Russia.

Keywords: culture, values, economic behavior, economic attitudes, cross-cultural comparison

\section{Introduction}

Values are widely used in applied research in social psychology (Bardi \& Schwartz, 2003; Knafo, Roccas, \& Sagiv, 2011). Schwartz (1992) defined values as motivational, trans-situational goals that serve as guiding principles in people's lives. Values 
affect the evaluation of events and people (Kluckhohn, 1951; Rokeach, 1973; Rohan, 2000), as well as attitudes, choices, and decisions (Knafo, Daniel, \& KhouryKassabri, 2008; Maio, Pakizeh, Cheung, \& Rees, 2009; Feather, 1995; Schwartz, 2006; Verplanken \& Holland, 2002).

In this study, we regard values as personal constructs that can shed light on the motives for economic behavior. As shown in several studies, values motivate people's behavior (Rokeach, 1973). Nevertheless, there are other approaches stating that human behavior is not driven by values only (Kristiansen \& Hotte, 1996; McClelland, 1985). For example, McClelland argues that values are likely to influence behavior only when it stems from conscious decisions (McClelland, 1985).

To increase the predictability of value measurements for behavior, it is important to examine the mechanisms that link values and behavior. First, a certain value might be actualized in a specific situation (for example, a report about a major accident or terrorist attack is likely to activate the value of Security). A study by Verplanken and Holland showed that the priming of a certain value intensifies the behavior aimed at finding information relevant to the given value and affects coordination of behavioral choices with this value (Verplanken \& Holland, 2002). The relation between values and behavior is based on the fact that elements of the situation (which activate the relation) relevant to certain values become the focus of human attention. In this case, the situation is understood and interpreted, based on the value priorities of an individual (Karp, 1996; Bond \& Chi, 1997). More importantly, behavior that aims to realize the activated value becomes significant. Action planning is also facilitated in situations that rely on an important human value. In addition, planning increases resistance in the face of any obstacle that may arise during the implementation of actions aimed at the realization of the value (Goodwin et. al., 2002; Goodwin \& Tinker, 2002).

Currently, one of the most popular value theories is the theory of basic human values proposed by Schwartz. In his approach, Schwartz argues that the crucial aspect that distinguishes among values is the type of motivation in which they are reflected (Schwartz, 1992; 2006). Therefore, he grouped the individual values into sets of values (types of motivation) sharing a common goal. He argues that basic human values, which are recognized in all cultures, are those that represent universal human needs (biological needs, requisites of coordinated social interaction, and demands of group functioning) in the form of conscious goals. Based on the values selected by previous investigators, found in religious and philosophical works in different cultures, he has defined 10 distinct motivational types of values. These values are as follows: Self-Direction, Stimulation, Hedonism, Achievement, Power, Security, Conformity, Tradition, Benevolence, and Universalism. According to Schwartz, they determine the specific actions of an individual and his or her activity as a whole (Schwartz, 1990, 1995).

Schwartz and Bilsky developed a theory of dynamic relations among the major types of human motivation (Schwartz \& Bilsky, 1990). According to this theory, each motivation type has a goal that leads the desires of an individual; these desires, in turn, lead to compatible or contradictory actions. Thus, conflict or compatibility among the values determines, in the final analysis, the strategy of the individual's behavior. The authors proposed the following typology of contradictions between the values: 
1) Conservation values (Security, Conformity, and Tradition), as opposed to Openness to Change values (Stimulation, Self-Direction, and Hedonism). Here, there is an obvious conflict between values emphasizing independence of thought and action and values of preserving traditions and maintaining social stability.

2) Self-Transcendence values (Universalism and Benevolence), in contrast with Self-Enhancement values (Power, Achievement, and Hedonism). Here also, there is an apparent conflict between concern for the welfare of others and the pursuit of one's dominance over others.

Existing empirical studies have shown that basic values are related to different kinds of human behavior, including economic and political behavior. Caprara et al. (2006) showed that the values of Security and Power predicted a preference for right-wing, conservative parties, whereas the value of Universalism predicted a preference for left-wing, liberal parties (Caprara et al. 2006, 2008). The logic behind these relations, according to the researchers, is that people who value Security and Power expect that voting for the right will help to protect or realize their goals and serve to reaffirm their values. In the same way, voting for the left, with its policies promoting the objectives of Universalism, is considered by people to whom these values are important as a way to achieve their goals.

Later, Caprara, Vecchione, and Schwartz (2012) hypothesized that, in addition to the above-mentioned relations, there are some more complex mechanisms of influence of individual values on voting. The authors analyzed values as a means of predicting whether people will vote in elections. To explain the phenomenon of not voting using individual values, the authors used the following assumption: Since people who voted for the left or the right in the previous election gave preference to values of either Universalism or Security and Power, people who don't vote do not attach great importance to these values (therefore, voting for them is not a means of increasing the likelihood of achieving motivational goals important to them). As a result, it was found (in an Italian sample) that while those who voted for left-wing parties attributed more importance to Universalism, and rightwing supporters valued Security and Power, people who didn't vote attached significantly less importance to these three values (Caprara, Vecchione, \& Schwartz, 2012).

Thus, there are studies showing that values can explain or predict voting behavior. Accordingly, we can assume that there may be a relationship between value orientations and predispositions to economic behavior (Harrison, 1992; Harrison \& Huntington, 2000; Hofstede, 2001; Inglehart, 1997; Inglehart \& Baker, 2000).

Inglehart and Baker showed that Self-Expression values correlated with such indices as a country's GDP, human development index (HDI), share of service sector employment, social solidarity index, and internet use (Inglehart \& Baker, 2000). Schwartz showed that economic development indices were related positively to the values of Autonomy and Egalitarianism and negatively to Embeddedness and Hierarchy. Higher indices of democracy correlated positively with Autonomy, Egalitarianism, Mastery, and national prosperity levels. The values of Autonomy, Equality, and Harmony were related to lower levels of corruption, whereas those 
of Embeddedness, Hierarchy, and Mastery correlated positively with higher corruption levels (Schwartz, 2004; Lebedeva \& Tatarko, 2009).

However, the issue of the relationship between values and socioeconomic attitudes and behavior in Russia has not been studied enough; our study aims to fill in this gap.

The second question, closely related to the previous one, concerns the degree of stability and homogeneity of the value structure of Russians. If a relationship between values and predispositions to economic behavior is found, knowledge about the features of the temporal dynamics of the values of Russians and the differences in values of different groups of Russias population will allow for more accurate analyses of relevant differences and changes in economic behavior.

Studies on values demonstrated that in different cultures, Schwartz's individual values are distributed unequally (Magun \& Rudnev, 2010). This tendency becomes even stronger when the analysis is at the level of value oppositions. Since Russia is a multicultural state, we can also expect an uneven distribution of values among Russian citizens. In particular, previous studies have shown that the values of respondents from the North Caucasus differ from the values of Russians living in Moscow and Novokuznetsk (Lebedeva \& Grigoryan, 2013).

There are few systematic studies of the dynamics of Russian values. Previous studies conducted by the authors of this paper have shown that from 1999 to 2005, the values of young Russians have shifted to a greater preference for Autonomy (affective and intellectual) and Mastery (Lebedeva \& Tatarko, 2007). However, these studies were performed using a different methodology, which considered values at the cultural level. In the current study, we decided to analyze the dynamics of individual values of Russians, based on the latest data of systematic reviews (in particular, the data of the European Social Survey from 2006 to 2016) containing the short version of the Schwarz questionnaire.

\section{Research objectives:}

1. To reveal the dynamics of the value priorities of Russians from 2006 to 2016.

2. To identify the relationship between values and predispositions to economic behavior in various religious groups.

These tasks were performed in two studies.

\section{Method}

\section{Study 1.}

Participants. The first study was devoted to the analysis of the dynamics of values of Russians during the period from 2006 to 2016. In this part of the study, we used data from the European Social Survey (ESS, http://www.europeansocialsurvey. org/). We used only those ESS waves that included Russian data sets: 2006, 2008, 2010,2012 , and 2016. Each wave included a representative sample of about 2,500 respondents (Table 1). 
Table1

The characteristics of the Russian samples in the ESS

\begin{tabular}{ccrc}
\hline Year & N & Gender $(\mathbf{M} / \mathbf{F})$ & Age $($ Mean) \\
\hline 2006 & 2,437 & $983 / 1,454$ & 46 \\
2008 & 2,512 & $989 / 1,523$ & 47 \\
2010 & 2,595 & $1,064 / 1,531$ & 46 \\
2012 & 2,484 & $951 / 1,533$ & 45 \\
2016 & 2,430 & $1,037 / 1,393$ & 45 \\
\hline
\end{tabular}

Measures. The ESS questionnaire contained a shortened version of the Schwartz PVQ questionnaire, which includes 21 items for 10 values. The procedures for computing the scores for each value and centering them in sake of the proceeding analysis were performed according to Schwartz's instructions. In accordance with the key, an average rating was calculated for the 10 items, corresponding to the 10 types of motivation (or individual-level values) marked out by Schwartz: Power, Conformity, Benevolence, Security, Tradition, Universalism, Self-Direction, Stimulation, Hedonism, and Achievement (Schwartz, 1992). Additionally, the arithmetic means were calculated of four value oppositions (including 10 blocks of values) - which, according to the theory of Schwartz, are located along two axes: Conservation-Openness to change and Self-Transcendence-Self-Enhancement.

Analysis. The multivariate analysis of variance (MANOVA) test was used to measure the significance of value changes across several years, controlling for age and gender. Before performing the MANOVA, it was necessary to check the multivariate normality, linearity, and multivariate homogeneity of variance between groups, which were tested using QQ plots and histograms, Pearson's $r$ test, and Levene's test. Tukey's HSD was performed for those variables that were significant in the MANOVA.

\section{Study 2.}

Participants. Table 2 shows the characteristics of the second study sample. The sociopsychological survey was conducted in three regions of Russia. By ethnic composition, the sample included Russians (from Moscow and the North Caucasus Federal District) and representatives of the North and South Caucasus (Chechens, Ossetians, Balkars, Dagestanis, Armenians, and Georgians). The Russians, Armenians, and Ossetians identified themselves as Christians, whereas the Chechens and Balkars identified themselves as Muslims. A comparison was made between the Russians and the representatives of the Caucasian peoples as well as between Christians and Muslims. We used a "snowball" sampling strategy in five regions of Russia. The questionnaire took approximately 40 minutes to complete. This part of the study was conducted in 2010 . 
Table 2

The characteristics of the Study 2 sample

\begin{tabular}{llccc}
\hline \multicolumn{1}{c}{ Region } & \multicolumn{1}{c}{ Ethnic Group } & N & Gender M/F & Age (Mean) \\
\hline Moscow and & Russians & 221 & $92 / 129$ & 22 \\
Moscow region & Peoples of the South Caucasus & 13 & $5 / 8$ & 20 \\
\hline Stavropol region & Russians & 56 & $20 / 36$ & 20 \\
& Peoples of the North Caucasus & 40 & $13 / 27$ & 20 \\
\hline North Ossetia-Alania & Ossetians & 45 & $17 / 28$ & 31 \\
\hline Chechnya & Chechens & 37 & $16 / 21$ & 30 \\
\hline Kabardino-Balkaria & Balkars & 100 & $48 / 52$ & 29 \\
\hline
\end{tabular}

\section{Measures.}

1. Schwartz's survey (SVS) included 57 value items (see Lebedeva \& Tatarko, 2011). In accordance with the key, an average rating was calculated for the 10 types of individual-level values.

2. Attitudes toward economic behavior (Lebedeva \& Tatarko, 2011): When creating a methodology for evaluating models of economic behavior, 10 bipolar dimensions of economic behavior were developed (see below) according to which we constructed specific situational scenarios. Each situation represents a model in which a person might choose one of two opposite types of behavior, depending on his or her predispositions. The following types (dimensions) of economic behavior were evaluated in this study:

1. "Economic paternalism - Economic independence"

2. "Time saving - Money saving"

3. "Short-term - Long-term prospects in economic behavior"

4. "Wastefulness - Economy"

5. "Economic interest - Economic indifference"

6. "Priority of profit over the law - Priority of the law over profit"

7. "Economic activity - Economic inactivity"

8. "Acceptability of using loans in daily life - Unacceptability of using loans in daily life"

9. "Equal distribution of financial rewards - Fair distribution of financial rewards"

10. "Priority of the size of the financial reward - Priority of the creative aspect of work"

Analysis. The methods of the data processing were as follows: a t-test for independent samples and a multiple regression analysis. To control the sample size effect, we used Cohen's d coefficient (Cohen, 1988). 


\section{Results and Discussion}

\section{Study 1. Dynamics of values}

First, let us answer the following question: Have the individual values of Russians and their structure changed in 10 years? Having centered and separated the scores across rounds, we get the following results (Fig. 1):

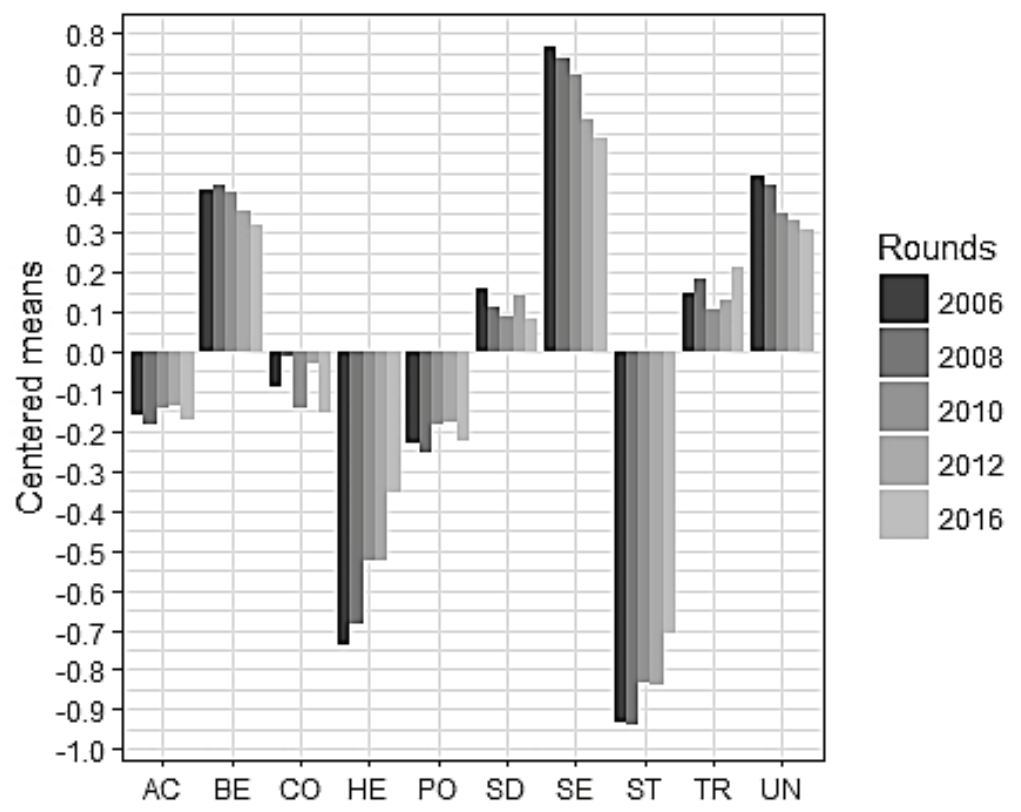

Figure. 1. Value priorities of Russians, 2006-2016.

Note: SE - "Security," CO - "Conformity," TR - "Tradition," BE - "Benevolence," UN - "Universalism," SD - "Self-Direction," ST - "Stimulation", HE - "Hedonism," AC - "Achievement," PO - "Power."

The higher the score in the histogram, the higher the manifestation of a certain value. It can be seen that the main priority among Russians is Security. Universalism and Benevolence have noticeably high scores in Russia as well. Tradition, Self-Direction, Conformity, Achievement, and Power, which score from 0.16 (more expressed) to -0.21 (less expressed) in Russia, form the next group of values. Hedonism and Stimulation are the least typical values among Russians.

The most visible trend of changes over years is that Russians seem to prefer such values as Hedonism and Stimulation more strongly year after year. Also we can see a tendency to gradually reducing scores of Benevolence, Security and Universalism, but at different rates. Upward trends for Achievement and Power, as well as downward changes for Conformity and Self-Direction, are less visible.

The MANOVA test for individual values. Since the MANOVA assumes multivariate normality, each group was checked for normal distribution using QQ plots and histograms, all of which gave satisfactory results.

Linearity (tested with Pearson's r) was true for the values across rounds, except for Tradition, Achievement, and Power, which showed p-values above the threshold of 0.05 . 


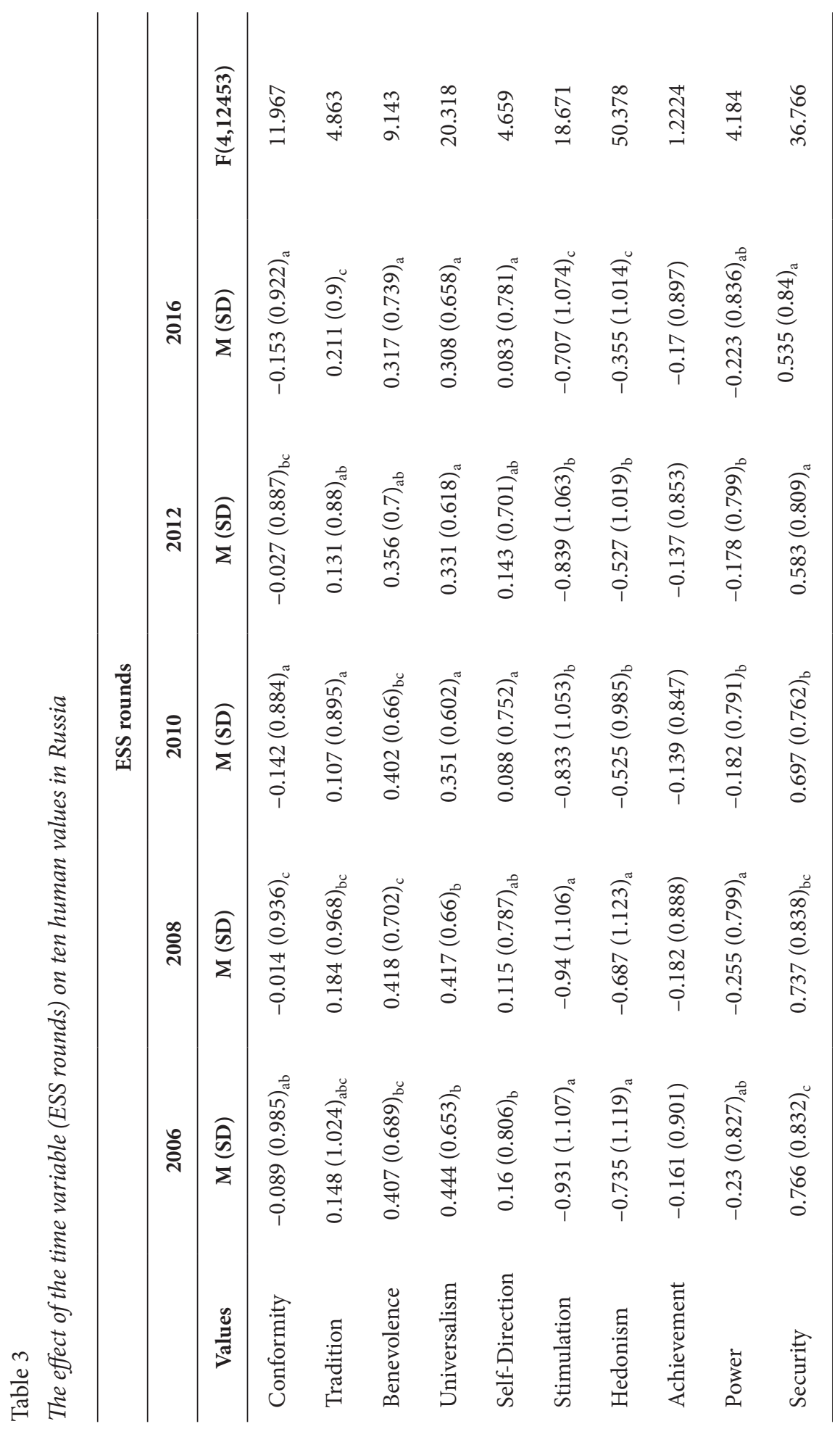


Homoscedasticity was tested with Levene's test, and low p-values led to the conclusion that variances could not be assumed to be equal, so heteroscedasticity was indicated. However, the number of observations in each group was approximately the same, and the MANOVA was robust against heteroscedasticity, which means that it was still appropriate to conduct further analysis.

Having tested the data for necessary conditions for performing the multivariate analysis of variance, we moved to the main tests. A one-way MANOVA was conducted to compare the effect of rounds (years) on the expression of the ten human values.

The differences between the rounds of measurement were tested by pairwise comparisons using Tukey's HSD test. Values in rows with different indexes were statistically significantly different $(\mathrm{p}<.05)$.

A MANOVA for ESS rounds as an independent group and human values as dependent variables showed significant multivariate effects: Wilk's $\Lambda=0.963$, $\mathrm{F}(4,12453)=13.136, \mathrm{p}<0.001$. There was a significant effect of the time variable at the $\mathrm{p}<.05$ level on Conformity $[\mathrm{F}(4,12453)=11.967, \mathrm{p}<0.001]$, Tradition $[\mathrm{F}(4,12453)=4.863, \mathrm{p}=0.0006]$, Benevolence $[\mathrm{F}(4,12453)=9.143$, $\mathrm{p}<0.001]$, Universalism $[\mathrm{F}(4,12453)=20.318, \quad \mathrm{p}<0.001]$, Self-Direction $[F(4,12453)=4.658, p=0.0009]$, Stimulation $[F(4,12453)=18.671, p<0.001]$, Hedonism $[\mathrm{F}(4,12453)=50.378, \mathrm{p}<0.001]$, Power $[\mathrm{F}(4,12453)=4.184$, $\mathrm{p}=0.002]$, and Security $[\mathrm{F}(4,12453)=36.766, \mathrm{p}<0.001]$. The effects on Achievement $[\mathrm{F}(4,12453)=1.222, \mathrm{p}=0.299]$ appeared to be insignificant.

Generally, changes towards less similarity were significant for Benevolence, with the most difference between 2006 and 2016; for Conformity, there was a significant fluctuation between each year, but it was not significant between the first and the last years; and for Self-Direction, there was a noticeable change between 2006 and 2016, but each year did not significantly differ from the previous one. Security showed the greatest difference between 2010 and 2012, and the first round showed significantly more similarity than the last one; Universalism demonstrated a difference between 2008 and 2010, separating two periods that were similar to each other, but the general trend was toward less similarity.

For Hedonism, the most visible difference was revealed between the two last rounds; for Power, there was a difference between 2008 and 2010, but none between the first and the last years; and for Stimulation, there was a change between 2008 and 2010, as well as between 2012 and 2016, and also there was an overall change toward more similarity.

For Tradition, the changes were significant, but the first two rounds did not differ from the last two; only 2008 and 2010 demonstrated a difference from following rounds.

\section{Study 2. Relations between basic values and economic attitudes}

Furthermore, we examined the relationships between values and predisposition toward models of economic behavior. To demonstrate intercultural distinctions of values' impact on economic behavior, the two groups of respondents were divided by religion (instead of their ethnic identity). Because the respondents from the North Caucasian region included representatives of six ethnic groups, sam- 
ple crushing of these small groups would distance us from the overall objective, a cross-cultural comparison of values as a predictor of economic behavior. Besides, according to our previous research, the religious aspect played a significant differentiating role in choosing models of economic behavior (Lebedeva \& Tatarko, 2011).

First, we compared the value means of the groups based on religion. Table 4 shows the means and their differences between representatives of the Christian and Muslim faiths:

Table 4

Interfaith comparison of means of values (Christians and Muslims)

\begin{tabular}{lcccc}
\hline \multicolumn{1}{c}{ Individual values } & $\begin{array}{c}\text { M/SD } \\
\text { Christians } \\
(\mathbf{N}=393)\end{array}$ & $\begin{array}{c}\text { M/SD } \\
\text { Muslims } \\
(\mathbf{N}=165)\end{array}$ & $\mathbf{t}$ & Cohen's d \\
\hline Security & $4.39 / .64$ & $4.55 / .54$ & $-3.25^{* *}$ & .31 \\
Conformity & $4.17 / .67$ & $4.45 / .57$ & $-4.58^{\star * *}$ & .58 \\
Tradition & $3.15 / .87$ & $3.86 / .77$ & $-9.20^{* * *}$ & .62 \\
Benevolence & $4.35 / .58$ & $4.42 / .53$ & -1.71 & - \\
Universalism & $3.74 / .61$ & $3.88 / .55$ & $-2.48^{*}$ & .33 \\
Self-Direction & $4.29 / .67$ & $4.05 / .57$ & $3.97^{* * *}$ & .51 \\
Stimulation & $3.49 / 1.06$ & $2.96 / 1.19$ & $5.75^{* * *}$ & .61 \\
Hedonism & $3.82 / 1.06$ & $3.57 / 1.17$ & $2.39^{*}$ & .28 \\
Achievement & $3.99 / .64$ & $3.85 / .68$ & $2.32^{*}$ & .23 \\
Power & $3.33 / .94$ & $3.26 / 1.05$ & .92 & - \\
\hline
\end{tabular}

Note. ${ }^{*} p<0.05 ;{ }^{* *} p<0.01 ;{ }^{* *} p<0.001$

The interfaith comparison revealed significant differences: Christians attributed more importance to the values of Openness to Change (Self-Direction, Stimulation) and the values of Hedonism and Achievement, which contribute to the realization of individual goals; Muslims gave higher priority to the values of Conservation (Security, Conformity, Tradition) and Self-Transcendence (Universalism), which contribute to group survival and maintenance of group harmony. The measure of effect size (Cohen's d) showed that differences in the values of Conformity, Tradition, Stimulation, and Self-Direction were not accidental; these values reflected the differences in the conflicting values of Conservation (higher for Muslims) and Openness to Change (higher for Christians).

Second, we carried out an analysis of the differences in the relationships of values and models of economic behavior in the samples of Christians and Muslims separately. Multiple regression analysis was used for the data processing.

A regression analysis showed the relationships between Schwartz's individual values and individual choices in situations of economic behavior for Christians (see Table 5). The value of Tradition was related positively to the attitude for saving 


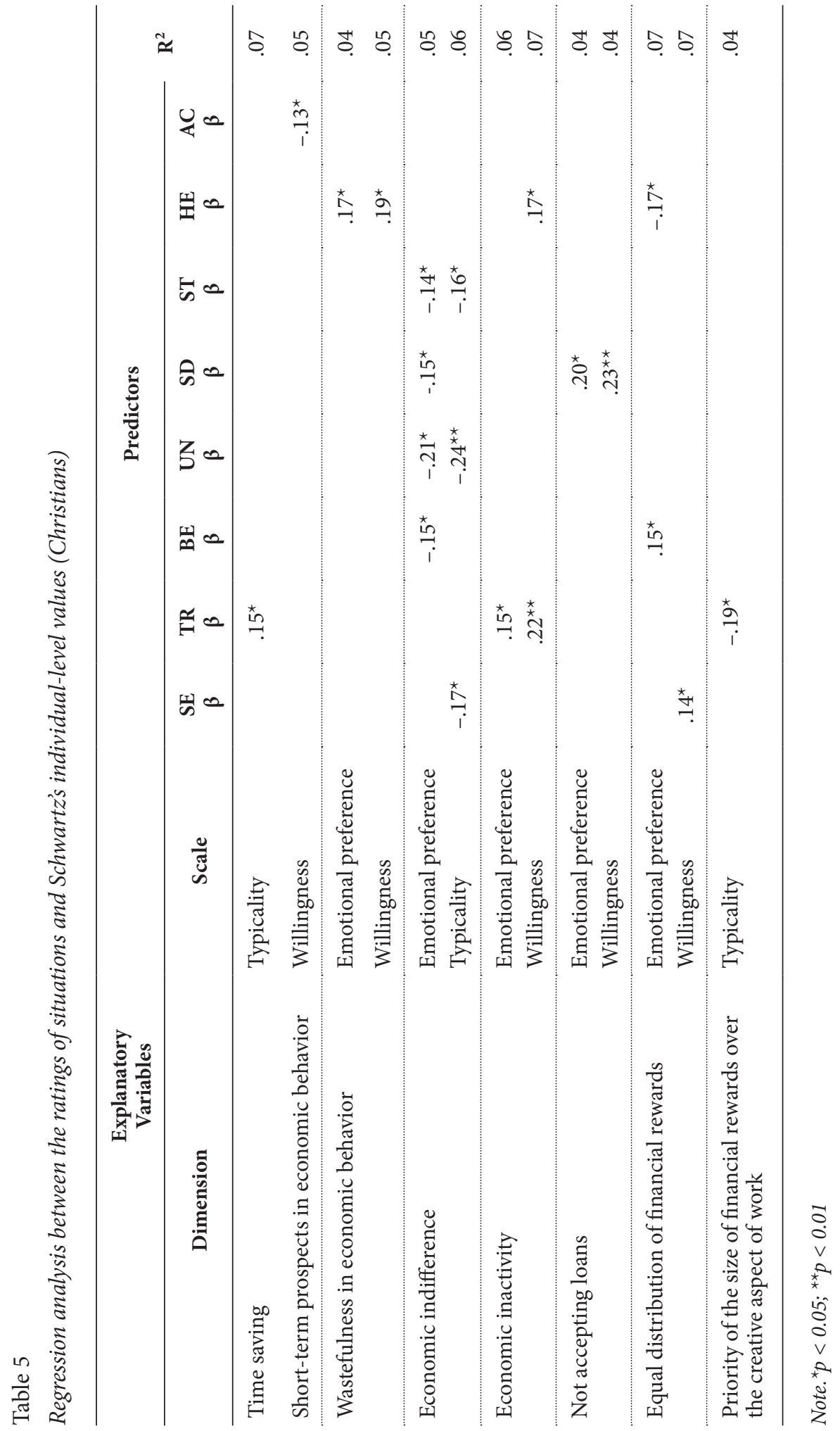


time. At the same time, the value of Tradition was positively associated with low economic activity of Christians. Such patterns of relationships among values and economic attitudes tells us that that money is not an important goal for Orthodox Christians in their lives.

Short-term economic prospects related negatively to the value of Achievement. That is to say, the value of Achievement in Christians called forth a long-term orientation of economic behavior.

Emotional preference for wastefulness in economic behavior and willingness to behave in this way related positively to the value of Hedonism, whereas the typicality of such behavior correlated negatively with the value of Security. The desire to enjoy one's life was the factor that contributed to the "recklessness" with which money was spent; the desire for security allowed for rating such behavior as less typical among Christians.

An emotional preference for economic indifference was negatively associated with the values of Benevolence, Universalism, and Stimulation. The ratings of the typicality of economic indifference correlated negatively with the values of Security, Universalism, and Stimulation. The same values of Stimulation and Universalism also elicited great interest in economic processes and phenomena; here, the influence of valuing Security also played a role. Apparently, the more the Christians appreciate Stimulation, Universalism, Benevolence, and Security, the more interested they are in economic development.

An emotional preference for economic inactivity was associated with the priority of Conformity, whereas at the behavioral level, correlations with values of Tradition and Hedonism were observed. Economic activity was associated with risks, stress, and changes, which do not correspond with the values of Conservation (Tradition and Conformity) or with the desire to enjoy life to the maximum (Hedonism).

The emotional unacceptability of loans in the sample of Christians correlated with the value of Self-Direction, and this is the value associated with reluctance to borrow; the more pronounced the value of Self-Direction, the more negative the person's attitude to loans was and the less he or she was willing to borrow.

The value of Hedonism was negatively associated with the emotional preference for fair distribution of financial rewards (instead of the principle of equal distribution), whereas the value of Security correlated positively with the willingness for such behavior. That is to say, the emotional component was associated with the desire to enjoy life; such desire correlated better with preference for equal distribution than with preference for fair distribution. That is, the desire for pleasure (the value of Hedonism) can lead to the acceptability of inequality, but the value of Security can reduce the willingness to distribute financial rewards unequally, because people understand that the situation of inequality is potentially dangerous for them. The priority of preferring money over creative work related negatively to the value of Tradition. Thus, we can assume that traditionally, money for Christians has less value than the possibility of creative work.

Next, we will consider the relationship between values and predisposition to models of economic behavior in the respondents who considered themselves Muslims (see Table 6). 


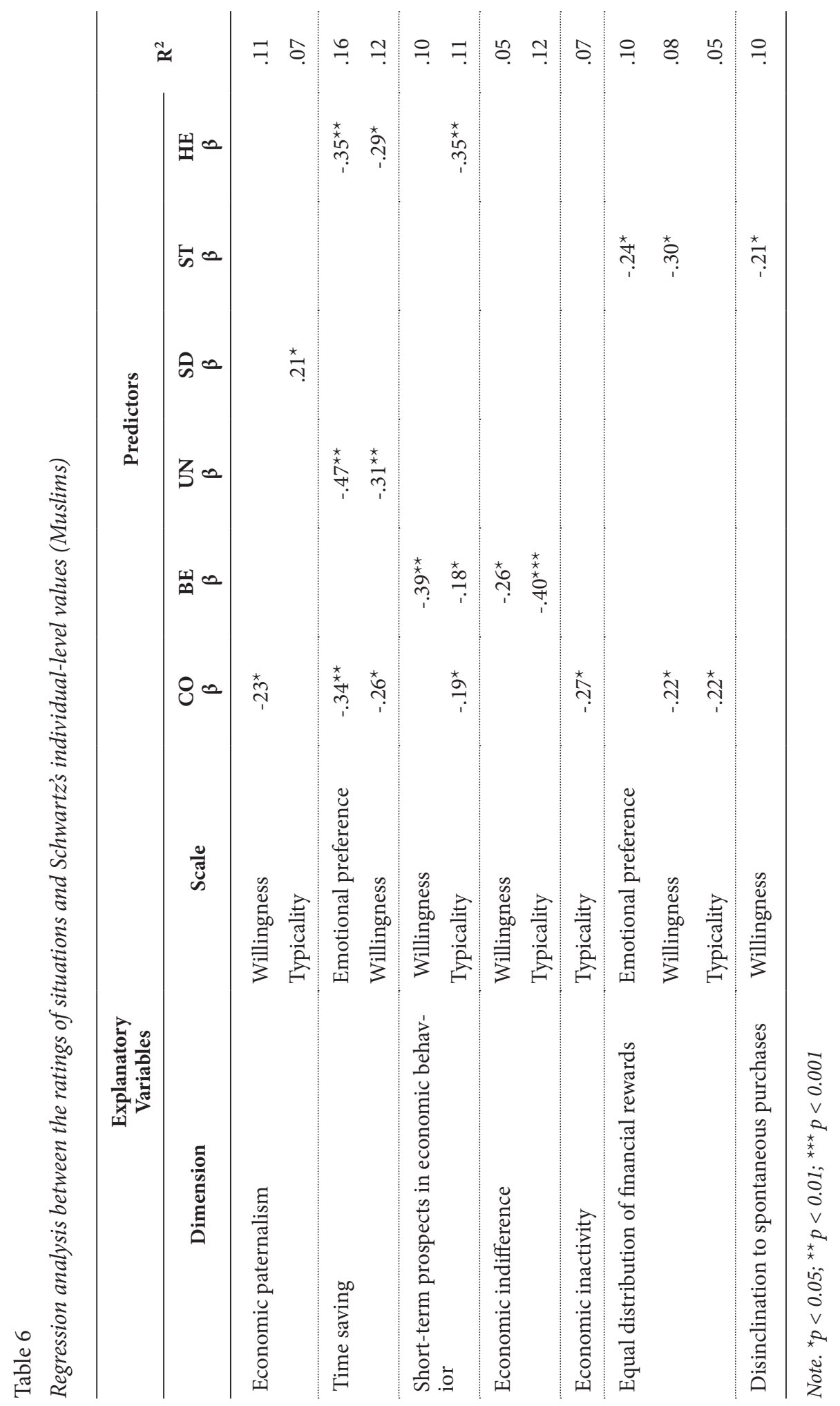


TIn Muslims, tolerance for economic paternalism correlated negatively with the value of Conformity; ratings for the typicality of economic paternalism correlated positively with the value of Self-Direction. A low value for Conformity predicted a higher level of economic paternalism, the desire to rely on the state to obtain their wealth. A high value for Self-Direction related to the typicality of such a pattern of behavior among Muslims. An emotional preference and willingness to spend money in order to save time negatively correlate with the values of Conformity, Universalism, and Hedonism. It can be concluded that for Muslims, it is preferable to save money rather than time, since the value of Conformity determines this choice. The relationships with Universalism and Hedonism are of particular interest here. Apparently, prioritizing money saving, in general, is typical for Muslim culture and is rated positively; therefore, such diverse values are associated with this choice.

The values of Benevolence and Hedonism relate negatively to willingness to take economic decisions based on short-term prospects. We can assume that Muslims are quite reasonable in planning, and therefore the desire to enjoy and care for loved ones does not correlate with quick and short-term income but rather with greater planning in economic behavior. The ratings of typicality of short-term prospects correlated negatively only with the value of Hedonism.

The value of Benevolence was associated negatively with the ratings of willingness and typicality of economic indifference of the person. It is important to understand that taking care of loved ones is a crucial component of Muslim culture, and therefore the value of Benevolence promotes interest in the economic side of life, reflecting the desire to create a favorable environment for relatives. This same feature is also reflected by the negative correlation between the values of Benevolence and the ratings of typicality of economic inactivity among Muslims. An emotional preference for the fair distribution of finances related negatively to the value of Stimulation; the willingness for such behavior correlated negatively with the value of Stimulation; and ratings of its typicality correlated negatively with the value of Conformity. It can be assumed that Muslims find fair distribution to be more secure; those appreciating Stimulation (risk, novelty) are not ready for such distribution, whereas those valuing Conformity do not consider this typical for their surroundings.

The value of Stimulation correlated negatively with a disinclination for emotional (spontaneous) purchases, which can be easily explained by the meaning of the value of Stimulation as a desire for a brighter and more eventful life, full of spontaneity and unexpected actions that bring joy. Thus, first of all, our data confirm the results of existing studies, demonstrating that values of people are of great importance for predicting their behavior (Kwang et al., 2005; Lönnqvist et al., 2006; Torelli \& Kaikati, 2009).

We can find empirical studies demonstrating that belonging to certain religious denominations could be associated with economic attitudes. A relationship was found between religious denominations and economic attitudes (Guiso, Sapienza, \& Zingales, 2003). Economic attitudes in their study included the following: people's attitudes toward cooperation, trust in the government and other government institutions, and attitudes toward law, the market economy, thrift, and competition. In the study by Guiso and colleagues, religiosity was positively associated with favorable attitudes toward the development of a free market and corresponding institutions. Religious people trusted other people and the government more, were less 
likely to break the law, and were more likely to believe in market justice. At the end of the paper, the authors concluded that Christians, in comparison with Muslims, were more inclined to support the values that promote economic growth (Guiso, Sapienza, \& Zingales, 2003).

How does religion influence economic attitudes? Susokolov (2006) described one of the possible mechanisms as the influence of religion on economic attitudes through basic values. Religion affects values, and values in turn affect economic attitudes.

In our study, we found that the basic values of Christians and Muslims related to their economic attitudes. However, our study showed that there are more differences in these relationships than similarities. The economic attitudes of Muslims and Christians related to different values. Thus, particular values may not always be considered universal predictors of the same economic attitudes across different cultural or religious groups. It is also important to take into account the sociocultural characteristics of the groups when considering the relationship between values and economic attitudes and behavior.

\section{Conclusion}

1. The main value that has been a priority for Russians is Security. However, the importance of this value decreased significantly during the period of 2006-2016. Such values as Achievement, Tradition, and Power are relatively stable among Russians. Such contrary values as Hedonism and Stimulation increased significantly from 2006 to 2016.

2. A relationship between values and attitudes toward different types of economic behavior was discovered. The patterns of these relationships are both similar and dissimilar in the samples of Christians (from the Central Federal District) and Muslims (from the North Caucasus Federal District) in Russia.

Summarizing the results of the study, we can say that the values of Christians and Muslims demonstrated different outcomes in terms of economic attitudes. The values of Christians indicate the low importance of money in comparison with other resources-creativity, time, etc. The values of Muslims, on the other hand, encourage them to favor economic activity, independence, and rationality in financial behavior.

\section{Acknowledgment}

This paper was supported by the Russian Science Foundation (Project No.17-7830035).

\section{References}

Bardi, A., \& Schwartz, S.H. (2003). Values and behavior:Strength and structure of relations. Personality and Social Psychology Bulletin, 29(10), 1207-1220. https://doi.org/10.1177/0146167203254602.

Bond, M.H., \& Chi, V. M.-Y. (1997). Values and moral behavior in mainland China. Psychologia: An International Journal of Psychology in the Orient, 40(4), 251-264.

Caprara, G.V., Schwartz, S., Capanna, C., Vecchione, M., \& Barbaranelli, C. (2006). Personality and politics: Values, traits, and political choice. Political Psychology, 27(1), 1-28. https://doi. org/10.1111/j.1467-9221.2006.00447.x. 
Caprara, G.V., Schwartz, S.H., Vecchione, M., \& Barbaranelli, C. (2008). The personalization of politics: Lessons from the Italian case. European Psychologist, 13(3), 157-172. https://doi. org/ 10.1027/1016-9040.13.3.157.

Caprara, G., Vecchione, M, \& Schwartz, S. (2012). Why people do not vote: The role of personal values. European Psychologist, 17(4), 266-278. https://doi.org/10.1027/1016-9040/a000099.

Cohen, J. (1988). Statistical power analysis for the behavioral sciences second edition. Lawrence Erlbaum Associates, Publishers.

Feather, N.T. (1995). Values, valences, and choice: The influences of values on the perceived attractiveness and choice of alternatives. Journal of Personality and Social Psychology, 68(6), 1135-1151. https://doi.org/10.1037/0022-3514.68.6.1135.

Goodwin, R., \& Tinker, M. (2002). Value priorities and preferences for a relationship partner. Personality and Individual Differences, 32(8), 1339-1349. https://doi.org/10.1016/ S0191-8869(01)00122-2.

Goodwin, R., Kozlova, A., Kwiatkowska, A., Luu, L.A.N., Nizharadze, G., Realo, A., ... \& Rämmer, A. (2003). Social representations of HIV/AIDS in Central and Eastern Europe. Social Science \& Medicine, 56(7), 1373-1384. https://doi.org/10.1016/S0277-9536(02)00135-1

Guiso, L., Sapienza, P., \& Zingales, L. (2003). People's opium? Religion and economic attitudes. Journal of Monetary Economics, 50(1), 225-282. https://doi.org/10.1016/S03043932(02)00202-7

Harrison, L.E. (1993). Who prospers: How cultural values shape economic and political success. New York: Basic Books. doi: 10.1016/S0277-9536(02)00135-1.

Harrison, L.E., \& Huntington, S.P. (2000) (Eds.). Culture matters: How values shape human progress. New York: Basic Books.

Hofstede G. (2001). Culture's consequences: Intern differences in work-related values. California, 2001.

Inglehart R. (1997). Modernization and postmodernization: cultural, economic and political change in 43 societies. Princeton, NJ: Princeton University Press.

Inglehart, R., \& Baker, W.E. (2000). Modernization, cultural change, and the persistence of traditional values. American Sociological Review, 65(1), 19-51. https://doi.org/10.2307/2657288.

Karp, D. G. (1996). Values and their effect on pro-environmental behavior. Environment and Behavior, 28(1), 111-133. https://doi.org/10.1177/0013916596281006.

Kenny, David A. (1987). Statistics for the social and behavioral sciences. Boston: Little, Brown.

Kluckhohn, C. (1951). Values and value-orientations in the theory of action. In T. Parsons \& E. A. Shils (Eds.), Toward a general theory of action (pp. 388-433). Cambridge, MA: Harvard University Press. https://doi.org/10.4159/harvard.9780674863507.c8

Knafo, A., Roccas, S., Sagiv, L. (2011). The value of values in cross-cultural research: A special issue in honor of Shalom Schwartz. Journal of Cross-Cultural Psychology, 42(2), 178-185. doi: $10.1177 / 0022022110396863$.

Knafo, A., Daniel, E., \& Khoury-Kassabri, M. (2008). Values as protective factors against violent behavior in Jewish and Arab high schools in Israel. Child Development, 79(3), 652-667. https://doi.org/10.1111/j.1467-8624.2008.01149.x.

Kristiansen, C.M., \& Hotte, A.M. (1996). Morality and the self: Implications for when and how of value-attitude-behavior relations. In C. Seligman, J. M. Olson, \& M. P. Zanna (Eds.), The Ontario Symposium: Vol. 8. The psychology of values (pp. 77-106). Hillsdale, NJ: Erlbaum.

Kwang, N.A., Ang, R.P., Ooi, L.B., Shin, W.S., Oei, T.P., \& Leng, V. (2005). Do adaptors and innovators subscribe to opposing values? Creativity Research Journal, 17(2-3), 273-281. https:// doi.org/10.1080/10400419.2005.9651485

Lebedeva N., \& Grigoryan L. (2013) 'Implicit theories of innovativeness: cross-cultural analysis', HSE Working Paper, Series: Sociology, Online http://www.hse.ru/data/2013/03/02/12932602 33/16SOC2013.pdf, downloaded 25 May, 2016 
Lebedeva N., \& Tatarko A. (2007). Tsennosti kulturi i razvitie obshchestv (The values of culture and development of society). Moscow: HSE publishing house.

Lebedeva N., \& Tatarko A. (2007). Kultura kak faktor obshchestvennogo progressa (Culture as a factor of social progress). Moscow: Yustitsinform.

Lebedeva N., \& Tatarko A. (Eds.). Tsennosti kulturi i modeli ekonomicheskogo povedeniya (The values of culture and the models of economical behavior), Moscow: Sputnik +, 2011.

Lönnqvist, J.E., Leikas, S., Paunonen, S., Nissinen, V., \& Verkasalo, M. (2006). Conformism moderates the relations between values, anticipated regret, and behavior. Personality and Social Psychology Bulletin, 32(11), 1469-1481. https://doi.org/10.1177/0146167206291672

Magun, V., \& Rudnev, M. (2010). The life values of the Russian population: Similarities and differences in comparison with other European countries. Russian Social Science Review, 51(6), 19-73. https://doi.org/10.2753/SOR1061-0154490401

McClelland, D. C. (1985). Human motivation. Glenview, IL: Scott, Foresman.

Rohan, M.J. (2000). A rose by any name? The values construct. Personality and Social Psychology Review, 4(3), 255-277. https://doi.org/10.1207/S15327957PSPR0403_4.

Rokeach, M. (1973). The nature of human values. New York: Free Press.

Schwartz, S.H. (1992). Universals in the content and structure of values: Theoretical advances and empirical tests in 20 countries. Advances in Experimental Social Psychology, 25, 1-65. https://doi.org/10.1016/S0065-2601(08)60281-6.

Schwartz S. (2004) Mapping and interpreting cultural differences around the world. H. Vinken, J. Soeters \& P. Ester (Eds.) Comparing cultures: Dimensions of culture in a comparative perspective (pp. 43-73). Leiden, The Netherlands: Brill.

Schwartz, S.H. (2006). Basic human values: Theory, measurement, and applications. Revue Française de Sociologie, 47, 249-288.

Schwartz, S.H., \& Bilsky, W. (1990). Toward a theory of the universal content and structure of values: Extensions and cross-cultural replications. Journal of Personality and Social Psychology, 58(5), 878-891. https://doi.org/10.1037/0022-3514.58.5.878.

Schwartz, S.H., \& Bardi, A. (1997). Influences of adaptation to communist rule on value priorities in Eastern Europe. Political Psychology, 18(2), 385-410. https://doi.org/10.1111/0162895X.00062

Schwartz, S.H., \& Huismans, S. (1995). Value priorities and religiosity in four Western religions. Social Psychology Quarterly, 58(2), 88-107. https://doi.org/10.2307/2787148

Susokolov, A.A. (2006). Kul'tura i obmen. Vvedenie v ekonomicheskuyu antropologiyu (Culture and exchange. An introduction to economic anthropology). Moscow: SPSL-Russkaya Panorama.

Torelli, C.J., \& Kaikati, A.M. (2009). Values as predictors of judgments and behaviors: The role of abstract and concrete mindsets. Journal of Personality and Social Psychology, 96(1), 231247. https://doi.org/10.1037/a0013836

Verplanken, B., \& Holland, R.W. (2002). Motivated decision making: Effects of activation and self-centrality of values on choices and behavior. Journal of Personality and Social Psychology, 82(3), 434-447. https://doi.org/10.1037/0022-3514.82.3.434

Original manuscript received February 12, 2018 Revised manuscript accepted July 31, 2018 First published online September 10, 2018 